\section{UJMM

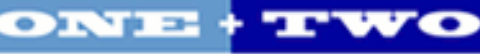

Volume 6 | 2016 Spring 2016

\section{Undergraduate Journal of Mathematical} Modeling: One + Two

2016

\title{
Maximum Efficiency of a Wind Turbine
}

Marisa Blackwood

University of South Florida

\author{
Advisors: \\ Arcadii Grinshpan, Mathematics and Statistics \\ Scott Campbell, Chemical and Biomedical Engineering \\ Problem Suggested By: Scott Campbell
}

Follow this and additional works at: https://digitalcommons.usf.edu/ujmm

Part of the Mathematics Commons

UJMM is an open access journal, free to authors and readers, and relies on your support:

Donate Now

\section{Recommended Citation}

Blackwood, Marisa (2016) "Maximum Efficiency of a Wind Turbine," Undergraduate Journal of Mathematical Modeling: One + Two: Vol. 6: Iss. 2, Article 2.

Available at: https://digitalcommons.usf.edu/ujmm/vol6/iss2/2 


\title{
Maximum Efficiency of a Wind Turbine
}

\begin{abstract}
The concept of a wind turbine is not new technology, however, in a day and age where renewable energy is popular, the interest in wind turbines has increased dramatically. This project investigates multiple aspects of a wind turbine and will derive the maximum power efficiency of an ideal wind turbine, first introduced by Albert Betz in 1919. This project will also calculate the size of a wind turbine at maximum efficiency given certain parameters and determine the optimum outlet velocity as a function of wind speed to maximize the mechanical energy produced. These equations will be derived by using concepts from physics and calculus, which will result in determining the optimal efficiency of an ideal turbine to be $59.26 \%$; this is referred to as The Betz Limit.
\end{abstract}

\section{Keywords}

Wind Turbine, Betz Limit, power efficiency

\section{Creative Commons License}

(c) (i) (3)

This work is licensed under a Creative Commons Attribution-Noncommercial-Share Alike 4.0 License. 


\section{PROBLEM STATEMENT}

A wind turbine works by converting kinetic energy into mechanical energy. Air approaches the turbine with the wind speed $v_{w}$ and leaves at a lower velocity $v_{2}$. If $v_{2}$ is almost as large as $v_{w}$, the turbine won't extract much kinetic energy. If $v_{2}$ is very low, then not much air will pass through the turbine. This suggests that there is an optimum outlet velocity $v_{2}$ that will maximize the amount of mechanical energy that can be produced. The purpose of this project is to determine the optimal outlet velocity as a function of the wind speed and the corresponding optimal efficiency of the wind turbine.

\section{MOTIVATION}

We live in a world powered by fossil fuels. However, these fossil fuels are a nonrenewable resource and are expected to run dry by the middle of the $21^{\text {st }}$ century (Britannica). A renewable resource is defined as "any natural resource that can be replenished naturally with the passage of time" (TheFreeDictionary.com). Over the past 40 years, with the rise of new ideas and technology, a transition to renewable energy has begun. This movement was spurred in the 1970s when oil prices leaped dramatically and motivated by the realization that fossil fuel abundance was being quickly depleted (US Department of Energy).

This switch was supported by those aware of the current status of climate change.

Climate change is a naturally occurring process whose rate has increased due to human activities, consisting mainly of fossil fuel consumption. Renewable energy such as wind, hydro, and solar power do not release harmful pollutants but the combustion of fossil fuels does.

When the sun heats the atmosphere unevenly, wind is used to distribute the excess heat; therefore, wind is considered a form of solar energy (US Department of Energy). The use of 
wind to create energy dates back to 5000 B.C. when it propelled boats down the Nile River (US Department of Energy). The popularity of windmills grew by the $11^{\text {th }}$ century and then took off during Industrialization when companies began to use windmills for electricity.

In harnessing energy from a wind turbine, the wind spins the blades of a turbine that then spins a shaft that is connected to a generator. This process converts the kinetic energy of the wind into mechanical energy. By using physics and calculus concepts, it is possible to derive formulas that represent the velocity that maximizes the turbine power and the maximum possible conversion efficiency of a wind turbine. These play an important in maximizing the amount of energy we can extract from the wind.

\section{MATHEMATICAL DESCRIPTION AND SOLUTION APPROACH}

Consider the Figure 1 below:

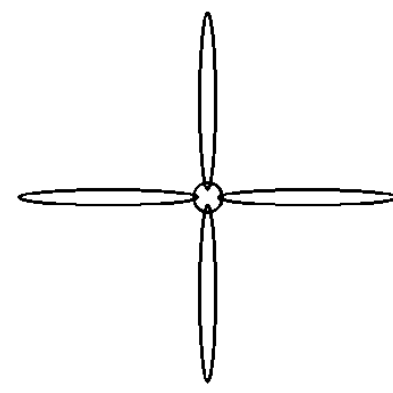

Front View

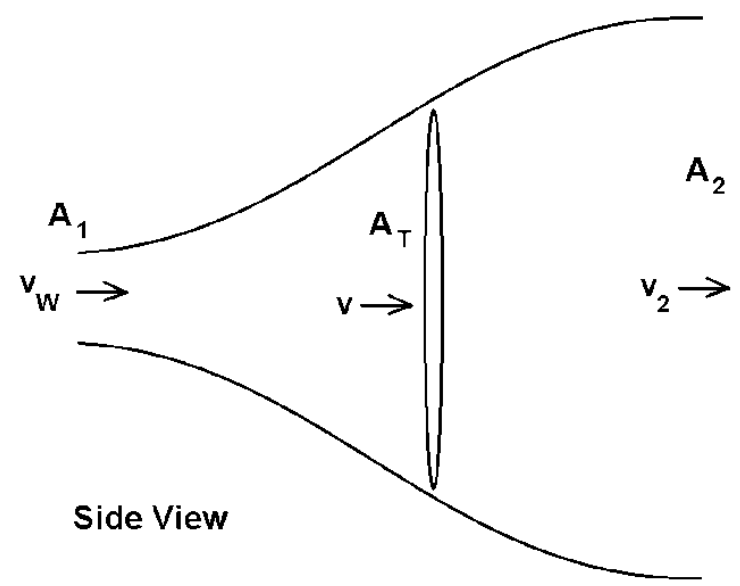

Figure 1: Profile of a wind turbine illustrating the path of airflow

Since the air is incompressible, the mass flow rate of air $(\mathrm{kg} / \mathrm{s}), \dot{m}$, can be defined as:

$$
\dot{m}=\rho A_{1} v_{w}=\rho A_{T} v=\rho A_{2} v_{2}
$$

where $\rho$ is the density of air $\left(\mathrm{kg} / \mathrm{m}^{3}\right), A_{1}$ is the is the cross-sectional area of the wind approaching the turbine, $A_{2}$ is the cross-sectional area of the air stream after the turbine, $A_{T}$ is the area of the 
turbine, $v_{w}$ is the upstream wind speed, $v$ is the air velocity at the turbine blades, and $v_{2}$ is the velocity of the downstream air after it has passed the turbine. The cross-sectional areas are in units of $\mathrm{m}^{2}$, and the airspeed (velocity) in $\mathrm{m} / \mathrm{s}$.

The rate at which kinetic energy is extracted from the wind is:

$$
P=\frac{\dot{m}}{2}\left(v_{w}^{2}-v_{2}^{2}\right)
$$

The rate at which kinetic energy is extracted from the wind is:

$$
P_{T}=\dot{m} v\left(v_{w}-v_{2}\right)
$$

Using the mass balance relationship at the turbine from equation (1) and substituting it into equations (2) and (3), results in:

$$
\begin{gathered}
P=\frac{\dot{m}}{2}\left(v_{w}^{2}-v_{2}^{2}\right)=\frac{\rho A_{T} v}{2}\left(v_{w}^{2}-v_{2}^{2}\right) \\
P_{T}=\dot{m} v\left(v_{w}-v_{2}\right)=\rho A_{T} v^{2}\left(v_{w}-v_{2}\right)
\end{gathered}
$$

From physics, we apply the law of conservation of energy and state that $P_{T}=P$, thereby setting equations (4) and equal to each other. This results in the following relationship:

$$
\frac{\rho A_{T} v}{2}\left(v_{w}^{2}-v_{2}^{2}\right)=\rho A_{T} v^{2}\left(v_{w}-v_{2}\right)
$$

which can be further reduced down to,

$$
\begin{aligned}
\frac{1}{2}\left(v_{w}-v_{2}\right)\left(v_{w}+v_{2}\right) & =v\left(v_{w}-v_{2}\right) \\
\frac{1}{2}\left(v_{w}+v_{2}\right) & =v
\end{aligned}
$$

This simply states that the airspeed at the turbine is the average of the airspeeds upstream and downstream from the turbine. Using this relationship, we can now restate the power extracted from the wind at the turbine, Equation (4), as: 


$$
P=P_{T}=\frac{\rho A_{T} v}{2}\left(v_{w}^{2}-v_{2}^{2}\right)=\frac{1}{4} \rho A_{T}\left(v_{w}^{3}-v_{w} v_{2}^{2}+v_{w}^{2} v_{2}-v_{2}^{3}\right)
$$

by factoring out the wind speed term, Equation (7) can be restated as:

$$
P_{T}=\frac{1}{4} \rho A_{T} v_{w}^{3}\left(1-\left(\frac{v_{2}}{v_{w}}\right)^{2}+\left(\frac{v_{2}}{v_{w}}\right)-\left(\frac{v_{2}}{v_{w}}\right)^{3}\right)
$$

To simplify the equation, let's define the following term:

$$
a=\frac{v_{2}}{v_{w}}
$$

Using this relationship, Equation (8) now becomes:

$$
P_{T}=\frac{1}{4} \rho A_{T} v_{w}^{3}\left(1-a^{2}+a-a^{3}\right)
$$

The results of Equation (10) show that the power extracted by the turbine is a function of the ratio of the downstream and upstream air velocities, $\frac{v_{2}}{v_{w}}$, and proportional to the cube of the upstream wind, $v_{w}^{3}$.

Consider the total rate of kinetic energy from the wind, $P_{\text {total }}$, passing through an equivalent area in the absence of a turbine. Determining this relationship will be key in determining the maximum efficiency of our ideal wind turbine.

From physics, we know that Power is defined as the incremental change in work over time, where work is equivalent to the kinetic energy of the wind. The kinetic energy of the wind is defined as:

$$
E=\frac{1}{2} m v^{2}
$$

The power can be calculated as:

$$
P=\frac{d E}{d t}=\frac{d}{d t}\left(\frac{1}{2} m v^{2}\right)
$$

Using the chain rule and equation (11) we have: 


$$
P=\frac{1}{2} \frac{d}{d t}\left(m v^{2}\right)=\frac{1}{2}\left(2 m v \frac{d v}{d t}+v^{2} \frac{d m}{d t}\right)
$$

In the absence of the turbine, the wind velocity, $v_{w}$, is constant so the $\frac{d v}{d t}$ term goes to zero. Using the results from equations (1) and (12) and remembering that the cross-sectional areas, $A_{1}, A_{T}, A_{2}$, in this case, are equivalent, the total power, $P_{\text {total }}$, can now be expressed as:

$$
P_{\text {total }}=\frac{1}{2} v_{w}{ }^{2} \frac{d m}{d t}=\frac{1}{2} v_{w}{ }^{2} \dot{m}=\frac{1}{2} \rho A_{T} v_{w}{ }^{3}
$$

Similar to the results found for the extractable turbine, the total power of the wind is proportional to the cube of the wind velocity.

Now that we have expressions for the power extracted at the turbine $\left(P_{T}\right)$ and the total power available from the wind $\left(P_{\text {total }}\right)$, we can now create an expression for the efficiency of the of the ideal wind turbine, $\eta=\frac{P_{T}}{P_{\text {total }}}$. Using the results from equations (10) and (13), the efficiency factor is:

$$
\eta=\frac{P_{T}}{P_{\text {total }}}=\frac{\frac{1}{4} \rho A_{T} v_{w}^{3}\left(1-a^{2}+a-a^{3}\right)}{\frac{1}{2} \rho A_{T} v_{w}^{3}}=\frac{1}{2}\left(1-a^{2}+a-a^{3}\right) .
$$

To determine the maximum possible efficiency, we will use Calculus to take the derivative of Equation (15) with respect to $a$, set it equal to zero, and solve for $a$.

$$
\frac{d \eta}{d a}=\frac{1}{2} \frac{d}{d a}\left(1-a^{2}+a-a^{3}\right)=\frac{1}{2}\left(-2 a+1-3 a^{2}\right)=\frac{1}{2}(1+a)(1-3 a)
$$

By inserting the relationship for $a$ from (9), we can state this in terms of the upstream and downstream velocities as:

$$
0=\frac{1}{2}(1+a)(1-3 a)=\frac{1}{2}\left(1+\frac{v_{2}}{v_{w}}\right)\left(1-3 \frac{v_{2}}{v_{w}}\right)
$$

This equation results in two solutions. The first solution, 


$$
0=\left(1+\frac{v_{2}}{v_{w}}\right), \Rightarrow v_{w}=-v_{2}
$$

which does not appear to be valid in a practical sense since the downstream airspeed cannot be in the opposite direction of the upstream wind.

The second solution results in:

$$
0=\left(1-3 \frac{v_{2}}{v_{w}}\right) \Rightarrow 3 v_{2}=v_{w} \quad \Rightarrow \quad v_{2}=\frac{1}{3} v_{w}
$$

This solution is more practical and significant in that it shows that in order to maximize the power from the turbine, the downstream airspeed must be equal to one-third of the upstream wind.

To determine the maximum efficiency factor numerically, we must take results from Equation (16) and insert them into Equation (14). From Equation (16), you can calculate the value of $a$ :

$$
a=\frac{v_{2}}{v_{w}}=\frac{1}{3}
$$

This results in Equation (15) becoming:

$$
\eta=\frac{1}{2}\left(1-\frac{1}{9}+\frac{1}{3}-\frac{1}{27}\right)=\frac{16}{27}=59.26 \%
$$

This is referred to as the Betz Limit and was first introduced by the German engineer Albert Betz in 1919 and published in 1926 with his book, "Wind-Energie und ihre Ausnutzung durch Windmühlen," or "Wind Energy and its Extraction through Wind Mills" (Ragheb and Ragheb). In order to build a turbine with the maximum efficiency, we will need to use the results that we have come up with so far and factor them into the expression for the power extracted by the turbine. To do so, we need insert Equation (14) into Equation (10):

$$
P_{T}=\frac{1}{4} \rho A_{T} v_{w}^{3}\left(1-a^{2}+a-a^{3}\right)=\frac{1}{2} \rho A_{T} v_{w}^{3} \eta
$$


In regards to the cross-sectional surface area of the turbine, we will assume it to be circular in nature with a diameter $D$. This results in the definition of:

$$
A_{T}=\frac{\pi D^{2}}{4}
$$

Equation (18) can now be stated as:

$$
P_{T}=\frac{1}{2} \rho A_{T} v_{w}^{3} \eta=\frac{1}{8} \rho D^{2} v_{w}^{3} \eta \pi \Rightarrow D=\sqrt{\frac{8 P_{T}}{\rho v_{w}^{3} \eta \pi}}
$$

Given the following parameters:

$$
P_{T}=1000 \mathrm{~W}, \quad v_{w}=10 \frac{\mathrm{m}}{\mathrm{s}}, \quad \rho=1.2 \frac{\mathrm{kg}}{\mathrm{m}^{3}},
$$

what would the diameter (in meters) of the turbine with maximum efficiency be?

Using the parameters given above and using the result from Equation (18) for maximum efficiency, Equation (21) can be solved with the following results:

$$
D=\sqrt{\frac{(8)(1000)}{(1.2)(10)^{3}(0.5926)(3.14)}}=1.892 \mathrm{~m}
$$

\section{DISCUSSION}

This project's goal was to solve four main questions. The first question was to find the optimum

outlet velocity as a function of the wind speed. We found this to be $v_{2}=\frac{1}{3} v_{w}$. In other words, the optimum amount of kinetic energy extracted from the wind is when the outlet velocity is equal to one-third the wind speed.

The second question was to determine the total rate of kinetic energy from the wind passing through an equivalent area in the absence of a turbine. This resulted in the following 
equation: $P_{\text {total }}=\frac{1}{2} \rho A_{T} v_{w}{ }^{3}$. This relationship was found to be proportional to the cube of the wind speed.

The third question was to determine the maximum possible conversion efficiency of a wind turbine. This was determined to be $59.26 \%$. This value was first introduced by German engineer Albert Betz in 1919 and is known as The Betz Limit. Practical turbines have efficiency factors more in the $40 \%$ range. This makes sense in the fact that a turbine cannot extract $100 \%$ of the kinetic energy of the wind; otherwise there would be no wind downstream.

The final question was to find the diameter needed of a wind turbine to produce 1000 watts of power from a wind at $10 \mathrm{~m} / \mathrm{s}$ while operating at maximum efficiency. This was calculated to be 1.892 meters. The objectives of this project were all met.

\section{CONCLUSION AND RECOMMENDATIONS}

The project was successful in deriving the maximum efficiently of a wind turbine as well as the optimal relationship between the outlet velocity and wind speed. After calculating these results, we must now look at the more practical applications of wind turbines. There are many factors that prevent wind turbines from reaching the theoretical Betz limit such as blade number losses, whirlpool losses, end losses and the airfoil profile losses (Cetin, Yurdusev and Ata). These losses prevent kinetic energy from being converted into mechanical energy. A further study recommendation would be to explore ways to reduce those losses and increase the efficiency of the practical wind turbine. 


\section{NOMENCLATURE}

\begin{tabular}{clc}
\hline Symbol & & \multicolumn{1}{c}{ Description } \\
\hline \hline$A_{1}$ & Cross-sectional area of the air upstream from the turbine & Units \\
$A_{2}$ & Cross-sectional area of the air downstream from the turbine & $\mathrm{m}^{2}$ \\
$A_{T}$ & Cross-sectional area of the of the air at the turbine & $\mathrm{m}^{2}$ \\
$\dot{m}$ & Mass Flow Rate of the air & $\mathrm{m}$ \\
$P_{T}$ & Power extracted at the turbine & Watts, $\left[\mathrm{kg} \cdot \mathrm{m}^{2} / \mathrm{s}^{3}\right]$ \\
$P_{t o t a l}$ & Total power available from wind & Watts, $\left[\mathrm{kg} \cdot \mathrm{m}^{2} / \mathrm{s}^{3}\right]$ \\
$v_{2}$ & Downstream air velocity & $\mathrm{m} / \mathrm{s}$ \\
$v_{w}$ & Upstream air velocity & $\mathrm{m} / \mathrm{s}$ \\
$D$ & Diameter of the turbine & $\mathrm{m}$ \\
$v$ & Air velocity at the turbine & $\mathrm{m} / \mathrm{s}$ \\
$\eta$ & Efficiency factor of the turbine & - \\
$\rho$ & Density of air & $\mathrm{kg} / \mathrm{m}^{3}$ \\
$A_{1}$ & Cross-sectional area of the air upstream from the turbine & $\mathrm{m}$
\end{tabular}

\section{REFERENCES}

Britannica. The New Encyclopedia Britannica. 1st. Chicago: Encyclopedia Britannica, Inc., 2005.

Cetin, N.S., et al. "Assesment of optimum tip speed ratio of wind turbines." Math Comput Appl 10.1 (2005): 147-154.

Ragheb, M. and A.M. Ragheb. Wind Turbines Theory - The Betz Equation and Optimal Rotor Tip Speed Ratio, Fundamental and Advanced Topics in Wind Power. Ed. R. Carriveau. InTech, 2011. <http://www.intechopen.com/books/fundamental-and-advanced-topics-inwind-power/wind-turbines-theory-the-betz-equation-and-optimal-rotor-tip-speed-ratio> . 
TheFreeDictionary.com. Renewable Resource. n.d. 25 April 2014.

<http://www.thefreedictionary.com/renewable+resource $>$.

US Department of Energy. History of Wind Energy. n.d. 25 Apr. 2014.

<http://energy.gov/eere/wind/history-wind-energy>.

—. How Do Wind Turbines Work? n.d. 24 April 2014. <http://energy.gov/eere/wind/how-dowind-turbines-work>. 